\title{
Implementasi Cloud Computing Menggunakan Metode Pengembangan Sistem Agile
}

\author{
Much Aziz Muslim ${ }^{1}$ \& Nur Astri Retno ${ }^{2}$ \\ ${ }^{1}$ Program Studi Teknik Informatika, FMIPA UNNES, Semarang \\ ${ }^{2}$ Program Studi Statistika Terapan dan Komputasi FMIPA Unnes \\ Email: a212muslim@yahoo.com
}

\begin{abstract}
Abstrak. Cloud computing merupakan sebuah teknologi yang menyediakan layanan terhadap sumber daya komputasi melalui sebuah jaringan. Sumber daya yang di sediakan di dalam cloud computing meliputi mesin, media penyimpanan data, sistem operasi dan program aplikasi. Fitur dari cloud computing dipercaya akan jauh lebih hemat dan memuaskan. Masalah yang muncul adalah bagaimana mengimplementasi Cloud Computing dengan menggunakan Windows Azure Pack dan bagaimana provisioning Windows Azure Pack SQL Database. Fokus pada penelitian ini adalah pada proses deploying dan provisioning $S Q L$ Database Server. Pengimplementasian cloud computing menggunakan metode pengembangan sistem agile dengan langkah-langkah meliputi perencanaan, implementasi, pengujian (test), dokumentasi, deployment dan pemeliharaan. Untuk menjalankan proses tersebut kebutuhan perangkat yang dipersiapkan meliputi perangkat keras seperti PC Server Cisco UCS C240 M3S2, Hardisk 8753 GB, 256 GB RAM, bandwith minimal 1 Mbps dan kebutuhan perangkat lunak meliputi Windows Server 2012 R2, VMM, Windows Azure Pack, IIS, SQL Server 2012 dan Web Patform Installer. Hasil dari implementasi cloud computing menggunakan metode pengembangan sistem agile adalah terbentuknya sebuah sistem cloud hosting provider dengan menggunakan Windows Azure Pack dan SQL Server 2012 sebagai sistem utama dan pengelolaan database menggunakan Microsoft SQL Server Management.
\end{abstract}

Kata kunci: Cloud Computing; Database; SQL; cloud hosting.

\section{PENDAHULUAN}

Perkembangan teknologi informasi yang sangat pesat telah membuat banyak perubahan bagi kehidupan manusia. Salah satu sistem informasi yang berkembang saat ini adanya sistem informasi awan, atau disebut Cloud Computing. Cloud Computing adalah sebuah model client-server, di mana resources seperti server, storage, network dan software dapat dipandang sebagai layanan yang dapat diakses oleh pengguna secara remote dan setiap saat [1]. 
Banyak kalangan masyarakat yang ingin mengadopsi teknologi cloud computing sebagai layanan cloud hosting provider. Berdasarkan latar belakang di atas masalah yang akan dikaji, bagaimana implementasi cloud computing dengan menggunakan Windows Azure Pack dan bagaimana cara provisioning Windows Azure Pack SQL Database. Batasan pada penulisan ini adalah pada proses deploying SQL Database Server dan Provisioning SQL Database menggunakan Windows Azure Pack.

\section{METODE}

Dalam pembuatan sistem cloud hosting di PT. Erudeye Indonesia digunakan metode agile. Metode agile adalah metodologi pengembangan perangkat lunak yang didasarkan pada prinsip-prinsip yang sama atau pengembangan sistem jangka pendek yang memerlukan adaptasi cepat dari pengembang terhadap perubahan dalam bentuk apapun. Langkah-langkah yang digunakan dalam metode agile yaitu perencanaan, implementasi, pengujian (test), dokumentasi, deployment dan pemeliharaan.

\subsection{Perencanaan Sistem}

Perencanaan sistem merupakan suatu tahap awal dalam pembuatan sistem yang memerlukan sutau proses atau tahap-tahapan. Adapun tahap-tahapan dalam perencanaan sistem cloud hosting yaitu tahap analisis sistem dan spesifikasi kebutuhan sistem.

Dalam tahap analisis system ini akan dirancang suatu layanan cloud yang dapat disesuaikan dengan kebutuhan dan permintaan pelanggan yaitu layanan cloud hosting dengan layanan database cloud menggunakan SQL Database.

Untuk mewujudkan adanya layanan cloud hosting, dibutuhkan sebuah perangkat komputer server dan sistem yang mampu memberikan layanan selfservice yang dapat memungkinkan pengguna melakukan full control terhadap web server mulai dari pemilihan perangkat server yang akan digunakan seperti halnya harddisk, RAM, bandwith, operating system dan aplikasi yang akan digunakan sebagai server serta kapasitas SQL database yang akan digunakan. Apabila cloud computing ini sudah diterapkan maka customer bisa menambahkan add-on tertentu pada database website-nya tanpa harus menghubungi bagian administrasi dan jika ingin membuat virtual machine, customer tidak harus menunggu persiapan dari administrasi tetapi customer dapat langsung membuat serta memilih layanan ataupun jenis virtual machine untuk SQL database server yang dinginkan. 
Untuk memperoleh sistem baru maka dibutuhkan spesifikasi kebutuhan system untuk meningkatkan layanan server hosting menjadi cloud hosting yang terperinci. Analisis kebutuhan dilakukan pada setiap komponen-komponen yang terkait.

Untuk melakukan konfigurasi sistem cloud hosting dibutuhkan beberapa perangkat guna mendukung cloud server, baik perangkat keras (Hardware) maupun perangkat lunak (Software). Berikut adalah spesifikasi perangkat yang digunakan dalam sistem cloud hosting.

Spesifikasi perangkat keras yang dibutuhkan dalam membangun sistem cloud hosting.

1) PC Server Cisco UCS C240 M3S2

2) Hardisk $8753 \mathrm{~GB}$

3) 256 GB $R A M$

4) Bandwith minimal $1 \mathrm{Mbps}$

Spesifikasi perangkat lunak yang dibutuhkan dalam membangun sebuah sistem cloud hosting khususnya SQL database server.

1) Windows Server 2012 R2

2) VMM

3) Windows Azure Pack

4) IIS

5) SQL Server 2012

6) Web Platform Installer

Operating System yang digunakan berbasis Windows dikarenakan Windows Azure Pack hanya dapat berjalan diatas operating system minimal berbasis Windows Server 2012. Pada Gambar 1 merupakan gambaran dari analisis kebutuhan perangkat dalam membangun sistem cloud hosting khususnya kebutuhan SQL database server. 


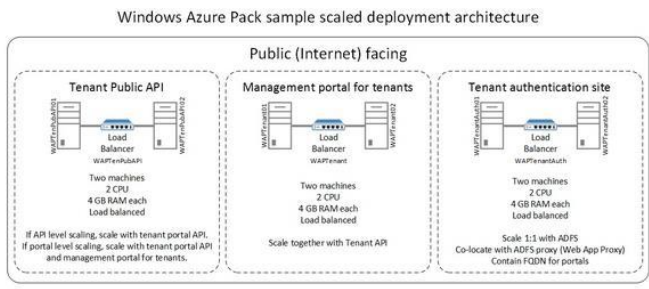

Gambar 1. Kebutuhan perangkat.

\subsection{Implementasi}

Setelah dilakukan analisis sistem dan penentuan kebutuhan perangkat maka langkah selanjutnya adalah pengimplementasian deploying dan provisioning sistem yaitu persiapan menu untuk customer, penginstallan dan konfigurasi terhadap perangkat keras dan perangkat lunak yang dibutuhkan untuk dapat meletakkan SQL Database pelanggan ke pusat data.

Sebelum dilakukan proses deploying dan konfigurasi sistem langkah yang harus dilakukan adalah mempersiapkan terlebih dahulu komputer server yang sudah di install operating system Windows Server 2012 R2, kemudian untuk langkah selanjutnya adalah installation SQL Server, Web Platform Installer dan add-on yang dibutuhkan dalam pembuatan SQL Database Server pada Windwos Azure Pack.

\subsection{Pengujian}

Sebuah Sistem hosting dapat dikatakan sebagai sebuah sistem cloud hosting ketika prasyarat layanan cloud computing dapat terpenuhi. Layanan cloud computing yang merupakan prasyarat utama dari sebuah sistem cloud computing meliputi Broad Network Access, Resource Pooling, Measured Services, Rapid Elasticity, Self Service. Pengujian sistem hosting adalah sebagai berikut:

\section{Broad Network Access}

Untuk menguji adanya layanan broad network access, komputer server yang berada dilokasi tertentu diuji dengan mengakses sistem tersebut dari luar jaringan lokal sistem dan hasilnya sistem berhasil diakses dari lokasi yang berada diluar jaringan lokal server. Dari hasil tersebut layanan broad network access pada sistem hosting terpenuhi.

\section{Resource Pooling}


Tahap resource pooling digunakan untuk menguji apakah database terpusat pada satu lokasi. Karena sudah jelas terbukti bahwa lokasi database-nya terpusat pada satu lokasi database, maka pengujian terhadap layanan resource pooling khususnya pada kategori media penyimpanan (storage) terpenuhi.

\section{Measured Services}

Pengujian terhadap layanan measured services dalam sistem hosting dapat dibuktikan, customer membayar sesuai dengan apa yang digunakan dan dapat dilihat sendiri oleh customer.

\section{Rapid Elasticity}

Adanya layanan rapid elasticity pada layanan hosting dapat dilihat pada saat customer ingin menambah besarnya volume virtual server-nya, customer dapat melakukannya sendiri dan customer akan dapat langsung memperoleh informasi mengenai biaya yang harus dikeluarkan.

\section{Self Service}

Adanya kemampuan self-service pada sistem hosting dapat dilihat pada saat customer akan membuat SQL Server untuk websitenya, customer dapat mengkonfigurasi sendiri $S Q L$ Servernya tanpa campur tangan admin.

\subsection{Tahap Dokumentasi}

Proses pendokumentasian perangkat dilakukan dengan cara capturing dan mencatat langkah demi langkah yang dilakukan dalam membangun sistem Cloud. Hasil dari capturing tersebut disusun dalam sebuah modul yang menjelaskan langkah demi langkah proses pembuatan serta cara penggunaan sistem.

\subsection{Tahap Deployment}

Proses deployment dilakukan dengan cara menyebarkan informasi mengenai layanan baru kepada para customer yang sebelumnya telah menggunakan server konvensional. Selain itu proses deployment juga dilakukan dengan cara publikasi melalui website resmi dari penyedia layanan hosting dan juga jejaring sosial.

\subsection{Tahap Pemeliharaan (Maintenance)}

Tahap pemeliharaan bertujuan untuk menjaga peralatan dan sistem dalam kondisi terbaik. Ketika dijalankan mungkin saja masih ada kesalahan kecil yang tidak ditemukan sebelumnya, atau ada penambahan fitur-fitur serta add- 
on yang belum ada pada software tersebut.

\section{HASIL DAN PEMBAHASAN}

\subsection{Desain Sistem}

Setelah dilakukan tahap analisis maka dihasilkan kebutuhan perangkat keras dan perangkat lunak. Pada tahap selanjutnya dibutuhkan desain sistem guna membatasi fungsi serta peranan di dalam sistem cloud hosting. Untuk menjelaskan fungsi dan peranan tersebut dibutuhkan desain virtual machine system dan desain privileged.

\subsubsection{Tampilan Antarmuka Web Platform Installer}

Seteleh Web Platform Installer berhasil di install maka langkah selanjutnya adalah menginstall add-on yang dibutuhkan dalam pembuatan SQL Database Server melalui Web Platform Installer. Add-on yang dibutuhkan dalam pembuatan SQL Database Server dengan Windows Azure Pack adalah sebagai berikut:

a. Admin API

b. Tenant API

c. Tenant public API

d. Admin authentication site

e. Tenant authentication site

f. Admin site (management portal for administrators)

g. Tenant site (management portal for tenants)

Pada Web Platform Installer kita pilih add-on yang dibutuhkan dalam pembuatan SQL Database Server dengan cara klik add, setelah semua yang dibutuhkan terpilih maka kita klik install seperti pada Gambar 2.

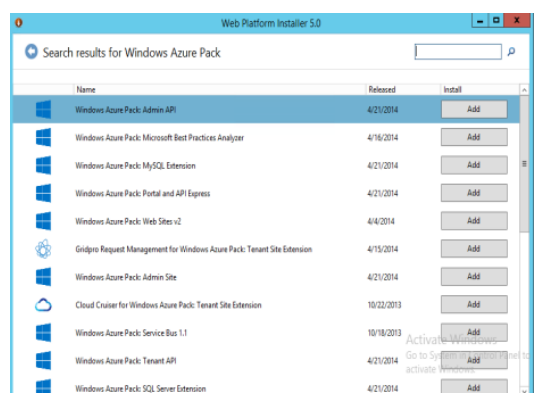

Gambar 2. Menu Web Platrform Installer. 


\subsubsection{Desain Virtual Machine System}

Desain virtual machine system merupakan rancangan yang menggambarkan fungsi serta peranan hardware dan software dalam sistem cloud computing. Pada Gambar 3 merupakan tampilan dari Desain virtual machine system.

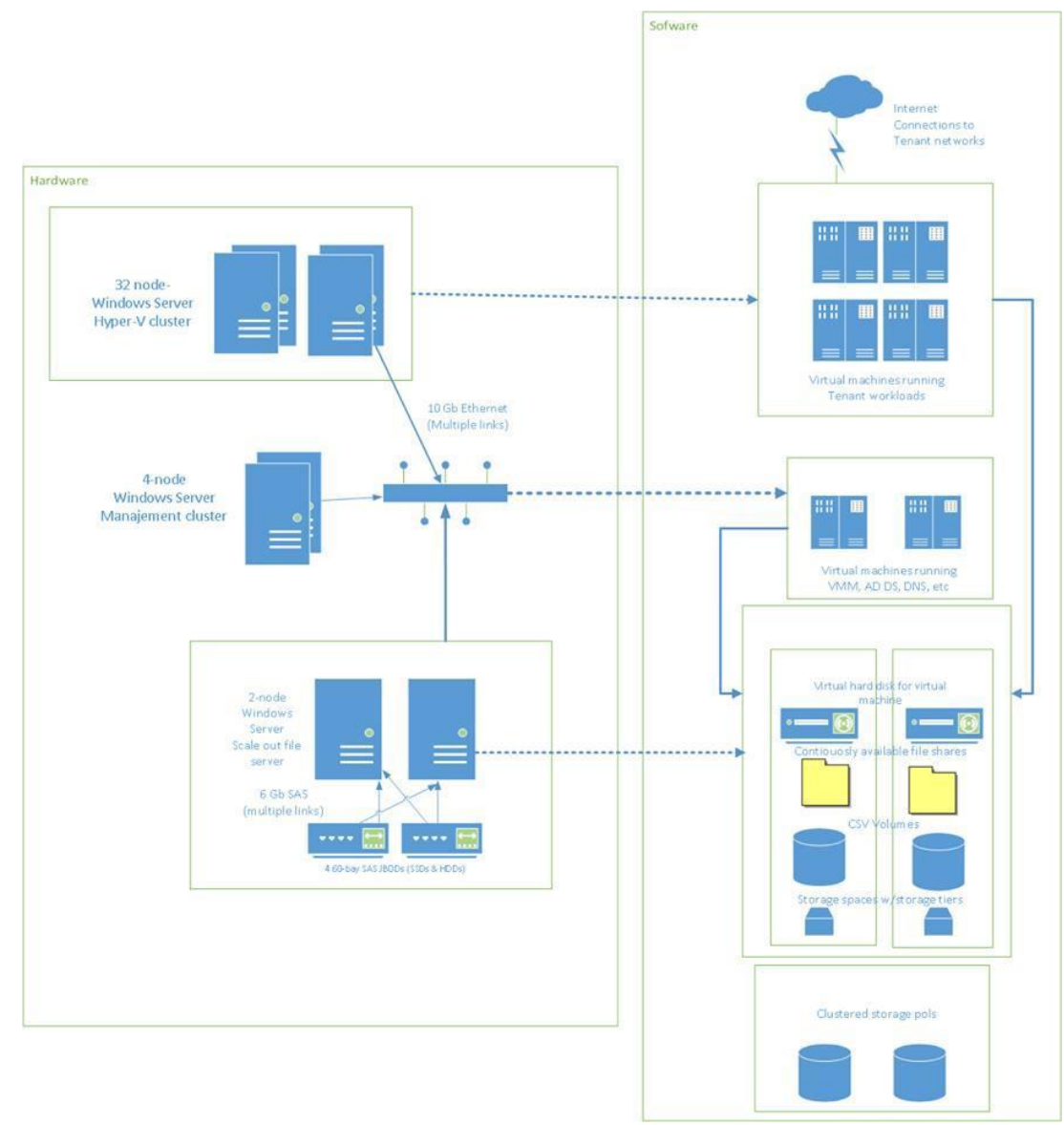

Gambar 3. Desain Virtual Machine System.

Berdasarkan pada Gambar 3 didapatkan bahwa layanan database terletak pada bagian virtual harddisk machine yang didukung oleh perangkat harddisk dan SQL server.

\subsubsection{Privileged}

Privileged services merupakan desain yang menjelaskan mengenai hak 
akses dari tiap pengguna dalam sistem cloud computing. Desain privileged tersebut dapat dilihat pada Gambar 3.

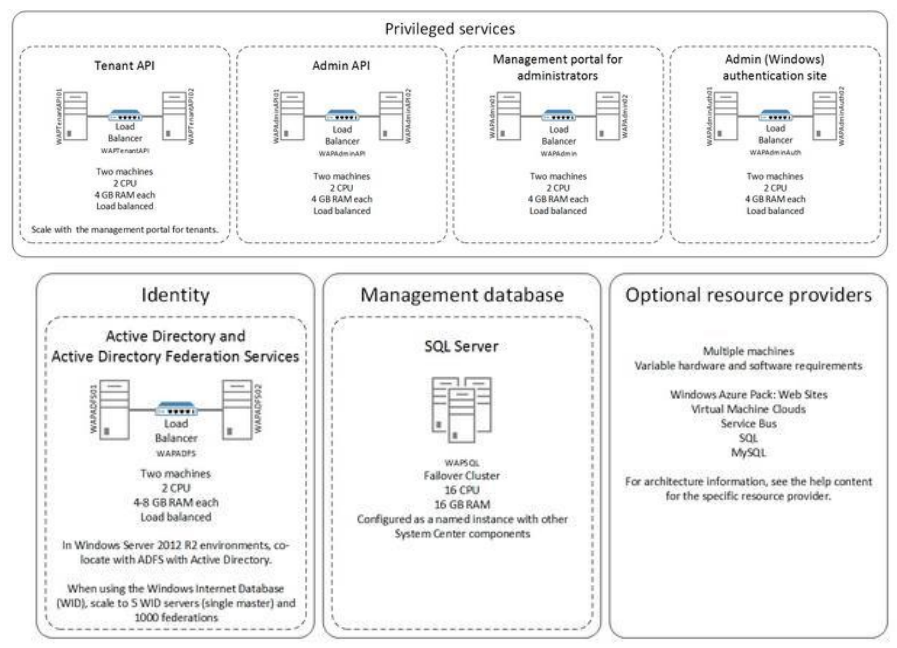

Gambar 3 Desain privileged.

Dari Gambar 3 didapatkan hak akses dan kebutuhan perangkat yang harus dipersiapkan dari tiap pengguna yaitu hak akses untuk customer atau tenant dan hak akses untuk admin. Dan dari privileged tersebut dapat dilihat bahwa customer dapat menentukan pilihannya sendiri dari hardware sampai software yang digunakan dalam menggunakan layanan cloud hosting.

\section{SIMPULAN}

Berdasarkan uraian pembahasan yang ada penulisan paper ini, maka dapat ditarik poin-poin kesimpulan sebagai berikut:

1. Implementasi Cloud Computing di PT. Erudeye Indonesia dibuat dengan melakukan proses deploying menggunakan metode pengembangan sistem agile development methods, dengan langkah meliputi perencanaan, implementasi, pengujian, dokumentasi, deployment dan pemeliharaan.

2. Proses provisioning pada sistem cloud hosting di PT. Erudeye Indonesia dibedakan menjadi dua macam provisioning, yaitu provisioning pada manajemen portal untuk admin dan manajemen portal untuk tenant. provisioning manajemen portal untuk admin digunakan untuk mempersiapkan dan membuat plan atau menu untuk customer sedangkan pada provisioning management portal untuk tenant digunakan untuk memilih plan atau menu yang akan digunakan untuk membuat database. 


\section{REFERENSI}

[1] Sofana, Iwan., Cloud Computing Teori dan Praktik (OpenNebula, Vmware dan Amazon AWS), Bandung: Informatika, 2012.

[2] -------, 2013. Install the Windows Azure Pack management portal, Microsoft Technet, Tersedia di http://technet.microsoft.com/enus/library/dn469340.aspx [diakses tanggal 6 Juni 2014]

[3] -------, 2013, Install the Windows Azure Pack Service Management APIs. Microsoft Technet, Tersedia di http://technet.microsoft.com/enus/library/dn469316.aspx [diakses tanggal 6 Juni 2014].

[4] -------, 2013, Windows Azure Pack components, Microsoft Technet, Tersedia di http://technet.microsoft.com/en-us/library/dn469332.aspx [diakses tanggal 6 Juni 2014].

[5] -------, 2013, Windows Azure Pack for Windows Server. Microsoft Technet. Tersedia di http://technet.microsoft.com/enus/library/dn296435.aspx [diakses tanggal 6 Juni 2014].

[6] Afrianto, Dedy Setyo., The Power of ownCloud. Yogyakarta: LeutikaPrio. Budiyanto. Alex. 2012. Pengantar Cloud Computing. Cloud Indonesia. Tersedia di http://alexbudiyanto.web.id [diakses tanggal 6 Juni 2014], 2013.

[7] Purbo, Onno W., Membuat sendiri Cloud Computing server menggunakan open source, Yogyakarta: Penerbit ANDI, 2012.

[8] Suherman., Panduan Praktis Windows Azure SQL Database, Jakarta: Elex Media Komputindo, 2013.

[9] Suryatama, Indra., Membangun infrastruktur komputasi awan privat menggunakan ubuntu enterprise cloud, Yogyakarta: Penerbit ANDI, 2012.

[10] Wahana Komputer., Konsep Jaringan Komputer dan Pengembangannya, Jakarta: Salemba Infotek, 2003. 
38 | Scientific Journal of Informatics, Vol. 1, No. 1, Mei 2014, ISSN 2407-7658 